\title{
The Differential Impact of Brand Equity on B2B Co-branding
}

\author{
Stavros P.Kalafatis ${ }^{1}$, Natalia Remizova ${ }^{2}$, Debra Riley ${ }^{3}$ and Jaywant Singh ${ }^{4}$
}

Stavros P. Kalafatis is Professor of Business Marketing at Kingston Business School, Kingston University. His research focuses on business segmentation, design of channels of distribution, relationship marketing and value creation. His research has been published, amongst others, in European Journal of Marketing, Industrial Marketing Management, Journal of Business Research, and Journal of Marketing Management.

Debra Riley is a researcher at Kingston Business School. Her research focuses on marketing strategy, new product development and innovation. She has extensive experience in industrial sales and marketing.

Jaywant Singh is Senior Lecturer at Kingston Business School, Kingston University. His research interests are primarily in the area of consumer behaviour and his research has been published in the International Journal of Market Research, European Journal of Marketing, and Journal of Business Ethics.

\footnotetext{
${ }^{1}$ Kingston Business School, Kingston University, Kingston Hill, Kingston-upon-Thames, UK KT2 7LB; Tel: +44(0) 208547 7121; email: kalafatis@kingston.ac.uk

${ }^{2}$ APC Global, Warnford Court, 29 Throgmorton Street, London, EC2N 2AT. Email: Natalia.remizova@apcglobal.co.uk

${ }^{3}$ Kingston University, Kingston Hill, Kingston-upon-Thames, UK KT2 7LB; Tel: +44(0) 208547 2000; email: d.riley@kingston.ac.uk
}

$\S$ Address for correspondence.

${ }^{4}$ Kingston Business School, Kingston University, Kingston Hill, Kingston-upon-Thames, UK KT2 7LB; Tel: +44(0) 208417 5158; email: j.singh@kingston.ac.uk

Note: The names of the authors appear in purely alphabetical order. 


\begin{abstract}
Purpose - Co-branding strategies are now seen increasingly in business-to-business (B2B) settings, however, there has been little research in this area. This study investigates the benefits of a B2B co-branding strategy where the partner brands have different brand equity positions.
\end{abstract}

Design/methodology/approach - This study used a scenario approach incorporating three real multimedia software brands and three fictitious brands in nine hypothetical alliances over 97 respondents. Using repeated measures ANOVA, the study examines the balance of benefits derived from brand partnerships between high-, medium- and low- brand equity levels firms.

Findings - The study found that brands with equivalent equity levels shared the benefits of the co-branding equally, while lower equity brands benefited more from the alliance than higher equity partners. The results also suggest that very dominant partners gain a greater proportion of functional benefits (such as technical expertise) from the co-branding strategy.

Research limitations/implications - The study used real and fictitious multimedia software brands in a hypothetical co-branding strategy, measuring a pre-defined set of benefits. Different results may be found selecting a different industry setting, brands, and benefits.

Practical implications - Firms sharing equal equity positions can expect to enjoy equivalent benefits from a co-branding strategy, regardless of how strong the joint equity position is. Before entering asymmetric co-branding relationships, firms should review the differential benefits expected and ensure that negotiations and success measures reflect the anticipated outcomes. Small firms wishing to pursue a co-branding partnership with a dominant market player should consider that they are less likely to capture the knowledgebased benefits from the brand alliance.

Originality/value - This paper is the first to look at the impact of asymmetric brand equity positions in a B2B co-branding partnership, and adds value to the literature and to practitioner understanding of the role of asymmetry in influencing co-branding outcomes.

Keywords co-branding, brand alliance, asymmetry, experimental design, repeated measures ANOVA, United Kingdom

Paper type Research paper 